\title{
Complex B Vitamins in Physical Exercise
}

\author{
Inês Gaspar \\ Psychologist at Inês Gaspar - Psychology and Mindfulness, Amsterdam-Oost, Nether lands
}

Submission: April 01, 2019; Published: May 22, 2019

*Corresponding author: Inês Gaspar, Psychologist at Inês Gaspar - Psychology and Mindfulness, Amsterdam-Oost, Nether lands

\begin{abstract}
The change of mentalities in our current society for prevention, physical exercise and nutrition have been increasingly prominent. Therefore, this article has as main objective to relate an adequate intake of micronutrients, mainly of the vitamins of the complex B. And in what way they can play an important role in the functionality of our organism, as well as in the performance during and after the physical exercise.

Keywords: Vitamins; Physical exercise; Complex B vitamins
\end{abstract}

\section{Introduction}

The balance between diet and regular exercise has been increasingly important to our current society and many studies have proven the importance of these two segments for a healthy life $[1,2]$. Given the current conjuncture of our society the populations are becoming more and more sedentary and food is increasingly deficient, with recourse mainly to processed foods rich in fats and sugars and poor in macronutrients and micronutrients important for a good body composition [1]. With this advancement of science in showing us that the impact of nutrition combined with good physical fitness plays a key role in the prevention of chronic diseases and management of the conditions of individuals already in the stage of disease [2] bringing numerous physiological and psychological benefits [3]. It is, therefore, necessary to perceive what food quality this is and how it influences the functionality of our organism [4].

It is therefore necessary to perceive and evaluate what more specific nutritional factors are then important for homeostasis with physical exercise and with our own well-being [5]. It is estimated that low physical fitness, namely, low cardiorespiratory fitness and low muscle strength and vitamin deficiencies are risk factors for long - term mortality [5]. Therefore, the effectiveness of supplementation of vitamins and minerals, especially of the B complex, is pointed out by several studies, since a diet rich in micronutrients is essential for the proper functioning of the body and brain [3]. Vitamins are important and necessary elements in small quantities, and these are not produced by our body and therefore we need to use external sources to suppress our needs, being the sources of animal or vegetable origin [6]. Each vitamin performs a specific function in our body and its deficiencies cause problems in the function they present, which can be considered as water soluble or liposoluble, those of the
B complex are in the first category and are not stored in our body for what is necessary a daily gain [6]. The vitamin content of the food is quite varied, depending on the plant, the species, the maturation stage, the harvesting period, genetic variations, post-harvest handling, storage conditions, processing and type of preparation [6].

Group B vitamins are required for various cortical processes involved in metabolism, such as the methylation of homocysteine to methionine (specifically B6, folic acid and B12), which is essential for the synthesis, repair and synthesis of DNA. other methylation reactions in the central nervous system [3]. The $B$ vitamins are B1, B2, B6, B12, folic acid, pantothenic acid, niacin and biotin [6]. In the case of vitamin B1 or thiamine, this is the most active form of thiamine pyrophosphate, and can be found in the diet in whole grains, wheat germ, yeast, soybean meal and wheat and pork [6]. Vegetables, fruits, eggs, chicken, mutton and ox are intermediate sources, whereas milk contains relatively low amounts of thiamine [7]. This has an important role in the well-being [7] and its storage is very little and can occur preferentially in the skeletal muscle, being half of its value absorbed, followed by the liver, heart, kidneys and brain and this storage increases little if large amounts were ingested $[6,7]$. The role of this vitamin is essential to help cells convert carbohydrates into energy and is necessary for the proper functioning of nerve cells and the brain [7]. Vitamin B1 is the most sensitive to temperature, and losses may occur during the thermal processing of foods and the recommended daily dose varies for men and women, due to differences in size and energy consumption [7].

Vitamin B2 acts as a redox cofactor in energy-generating metabolism, being essential for the formation of erythrocytes, 
neo-glycogenesis and regulation of thyroid enzymes, and helps cells convert carbohydrates into energy, being essential for the growth of cells, production of red blood cells and the health of the eyes and skin [6]. This vitamin loses its characteristics when exposed to light [6]. Riboflavin deficiencies are rare, since they are related to the metabolism of other vitamins, and a deficiency occurs when deficiency occurs [6]. The distribution of riboflavin in foods is wide, but its concentration is low. Among the food sources, milk and its derivatives, meat and viscera (such as liver and kidneys), green leafy vegetables (such as cabbage, broccoli, cabbage and watercress), eggs and peas can be highlighted [8].

In the case of the vitamin of vitamin B6 we can highlight the pyridoxine that represents the most stable form of this vitamin [9]. This in the body is converted to pyridoxal phosphate, which acts as a coenzyme of about 60 enzymes, most related to the metabolism of proteins and amino acids. This vitamin plays an important role in the synthesis of neurotransmitters such as noradrenaline, dopamine, serotonin and histamine. It also participates in amino acid degradation reactions, in which one of the end products is acetylcoenzyme A, necessary to produce energy and the synthesis of proteins, lipids and acetylcholine [9]. The sources of this vitamin are liver, cereal meal, yeast, crude cane molasses and wheat germ [9].

Vitamin B12 or cyancobalamin is only found naturally in foods of animal origin, such as in tissues, eggs and milk $[10,11]$. Vitamin B12 is an essential component of the proliferation and cellular differentiation of haematopoiesis and neurological functions, being essential for the synthesis of nucleic acids, erythrocytes and myelination [10,11]. Individuals consume about $2.4 \mu \mathrm{g}$ of vitamin B12 daily, of which only $50-60 \%$ are absorbed [12,13]. Vitamin B9 or folic acid, participates in the metabolism of amino acids and the synthesis of nucleic acids, being essential for the formation of blood cells and are important for biochemical processes, such as DNA synthesis and repair $[10,11]$.

The best sources of folic acid are viscera, beans and green leafy vegetables such as spinach, asparagus and broccoli. Other examples of foods are avocado, pumpkin, potato, beef, pork, carrot, cabbage, liver, orange, milk, apple, corn, egg, cheese. The body absorbs about $100 \%$ folic acid from supplements and fortified foods, but only two thirds of folic acid naturally present in food $[10,11]$.

\section{Discussion}

Vitamins mainly from B complex have potential ergogenic effects by adjusting the energetic metabolism of physical activities and improving exercise performance when supplemented $[14,15]$. This supplementation can be diffused in recreational and competition athletes, and these vitamins are particularly important in the practice of physical exercise because they are involved in the regulation of energy metabolism, modulating the synthesis and degradation of carbohydrates, fats and proteins
[16]. In the case of folic acid, it acts as an essential cofactor in methylation reactions, including in the formation of vitamin B12, among other important reactions [16]. Both B complex vitamins are involved as coenzymes of numerous regulatory enzymes [4], assisting cell division, nutrients eeses that are essential for growth, synthesis of new cells such as red blood cells, and for the repair of damaged cells and tissues [16]. In the degradation of amino acids such as valine, isoleucine, methionine and threonine and fatty acids, these amino acids are converted to propionyl$\mathrm{CoA}$ and the fatty acids are oxidized to acetyl-CoA and propionylCoA. Acetyl-CoA goes directly into the tricarboxylic acid cycle [16]. Propionyl-CoA is carboxylated in methyl malonyl-CoA and finally converted to succinyl-CoA by methyl malonyl-CoA mutase [14]. This enzyme requires vitamin B12 as a cofactor [16]. Thus, the state and needs for folic acid and vitamin B12 can be altered by energy production and reconstruction and repair of muscle tissue induced by physical activity [16]. The International Sports Nutrition Society recommends that energy requirements be scaled to activity level, body mass and mode of exercise [17] to ensure that specific individual needs are suppressed [17]. Achieving micronutrient sufficiency is an important concern for all athletes, so poorly planned diets can predispose individuals to micronutrient deficiency, regardless of predilection, which may have implications for athlete health and performance [17].

Thiamine, important in energy metabolism [18], is a coenzyme of pyruvate dehydrogenase that stimulates the conversion of pyruvate to acetyl-CoA and plays an important role in the metabolism of carbohydrates [14]. Decreasing thiamine concentration in cells provides degradation of enzyme activation, decreases ATP biosynthesis, and causes fatigue [14]. Such a low level of thiamine in the body can degrade exercise performance [14]. This vitamin, such as thiamine pyrophosphate, plays a key role in the metabolism of carbohydrates and proteins [14]. Nearly half of the thiamine in the body is stored in the muscles and thiamine is required for the normal functioning of skeletal and cardiac musculature, so thiamine may be a potentially limiting nutrient in physical activity [14]. Thiamine, also called vitamin B1, is an essential micronutrient and physical activity can affect the vitamin requirement, as well as sex, age and physiological state [15]. The active form of thiamine serves as a cofactor for the critical enzymes involved in glucose metabolism [15]. It functions as a catalyst in the generation of energy through the decarboxylation of branched-chain amino acids and alpha-keto acids and acts as a coenzyme for transketolase reactions in the form of thiamine pyrophosphate [15].

Riboflavin is an essential component of two coenzymes that participate in the transfer of electrons in energy metabolism, in amino acid metabolism and in the production of steroid hormones [17]. Riboflavin may increase the energy availability during oxidative metabolism [17]. In addition, despite the remarkable role of thiamine and riboflavin in energy turnover during exercise, the interaction between exercise and vitamins is poorly described in the literature [17]. 
Vitamin B6 has as its main function the metabolism of proteins and amino acids. Its most active form is pyridoxal 5'-phosphate, which is a cofactor for transaminases, decarboxylases and other enzymes used in the metabolic transformations of amino acids and nitrogen-containing compounds [19]. During exercise, the gluconeogenesis process involves the breakdown of amino acids to provide energy to the muscle and the conversion of lactic acid to glucose in the liver, several enzymes involved in this metabolically driven conversion [19]. Another function of vitamin $\mathrm{B} 6$ directly related to energy production during exercise is the breakdown of muscle glycogen. Vitamin B6 should be in adequate amounts to release glucose-1-phosphate from muscle glycogen since this vitamin is directly involved in amino acid metabolism [19]. The link between protein intake and vitamin B6 requirements is especially important for athletes because they generally have a greater need for protein than sedentary individuals and generally have a higher intake of this macronutrient because of the higher energy consumption [19]. Because exercise emphasizes metabolic pathways that use thiamine, riboflavin, and vitamin B6, the requirements for these vitamins may be high in athletes and active individuals. Theoretically, exercise increases the need for these nutrients due to decreased absorption, increased turnover, metabolism or loss of nutrients; biochemical adaptations associated with training; increased concentrations of mitochondrial enzymes that require the nutrient as cofactor; and the need for tissue maintenance and repair [19].

\section{Conclusion}

We conclude that not only should we emphasize an adequate and balanced intake of macronutrients, but also vitamins and minerals. As we can see throughout this article the correct intake mainly of B vitamins may have several implications for the proper functioning of the body, especially in individuals who practice physical exercise. Since these vitamins participate as cofactors, coenzymes, among other important functions in the reactions that occur either during or after the practice of physical exercise in various organs and tissues.

\section{Refrences}

1. Đorđić V, Božić P, Milanović I, Radisavljević S, Batez M, et. al (2019) Guidelines-Driven Educational Intervention Promotes Healthy Lifestyle Among Adolescents and Adults: A Serbian National Longitudinal Study Medicina (Kaunas) 55(2): E39.

2. Powell HS, Greenberg DL (2019) Screening for unhealthy diet and exercise habits: The electronic health record and a healthier population. Preventive Medicine Reports.

3. Saiki M, Matsui T, Soya M, Kashibe T, Shima T, et. al (2018) Thiamine tetrahydrofurfuryl disulfide promotes voluntary activity through dopaminergic activation in the medial prefrontal cortex. Scientific reports 8(1): 10469 .
4. Ford T, Downey L, Simpson T, McPhee G, Oliver, et. al (2018) The Effect of a High-Dose Vitamin B Multivitamin Supplement on the Relationship between Brain Metabolism and Blood Biomarkers of Oxidative Stress: A Randomized Control Trial. Nutrients 10(12): E1860.

5. Aparicio-Ugarriza R, Díaz ÁE, Palacios G, del Mar Bibiloni M, Julibert A, et. al (2018) Association between blood marker analyses regarding physical fitness levels in Spanish older adults: A cross-sectional study from the PHYSMED project. PloS one 13(10): e0206307.

6. Rubert A, Engel B, Rohlfes A, Marquardt L, de Monte Baccar N (2017) Vitaminas do complexo B: uma breve revisão. Revista Jovens Pesquisadores 7(1): 30-45.

7. Hernando-Requejo V (2018) Patología neurológica por déficit de vitaminas del grupo B: tiamina, folato y cobalamina. Nutrición Hospitalaria 35(6): 54-59.

8. Peechakara BV, Gupta M (2018) Vitamin B2 (Riboflavin) In Stat Pearls [Internet] StatPearls Publishing.

9. Aniceto C, Fatibello-Filho O (1999) Flow injection spectrophotometric determination of vitamin B6 (pyridoxine) in pharmaceutical formulations Química Nova 22(6): 805-809.

10. Güneş Ali, Aktar Fesih, Tan İlhan, Söker, Murat (2016) Niveles de moléculas de detección temprana de daño renal en la orina en niños con deficiencia de vitamina B12 Archivos argentinos de pediatría 114(5): 453-457.

11. Araya Q, Felipe, Arias S, Helga, Hernández (2016) Efectividad de la administración oral versus intramuscular de vitamina B12 en pacientes con deficiencia: revisión sistemática. Revista chilena de nutrición 43(2): 180-187.

12. Shipton MJ, Thachil J (2015) Vitamin B12 deficiency-A 21st century perspective. Clinical Medicine 15(2): 145-150.

13. Oliveira Martinho K, Araújo Tinôco AL, Queiroz Ribeiro A (2015) Prevalence and factors associated with vitamin B12 deficiency in elderly from Vicosa/MG, Brasil. Nutricion hospitalaria 32(5): 21622168.

14. Choi SK, Baek SH, Choi SW (2013) The effects of endurance training and thiamine supplementation on anti-fatigue during exercise. Journal of exercise nutrition \& biochemistry 17(4): 189-198.

15. Kim YN, Choi JY, Cho YO (2015) Regular moderate exercise training can alter the urinary excretion of thiamin and riboflavin. Nutrition research and practice 9(1): 43-48.

16. Kim YN, Hwang JH, Cho Y O (2016) The effects of exercise training and acute exercise duration on plasma folate and vitamin B12. Nutrition research and practice 10(2): 161-166.

17. Rogerson D (2017) Vegan diets: practical advice for athletes and exercisers. Journal of the International Society of Sports Nutrition 14(1): 36.

18. Huang WC, Huang HY, Hsu YJ, Su WH, Shen SY, et al. (2018) The effects of thiamine tetrahydrofurfuryl disulfide on physiological adaption and exercise performance improvement. Nutrients 10(7): E 851.

19. Manore MM (2000) Effect of physical activity on thiamine, riboflavin, and vitamin B-6 requirements. The American journal of clinical nutrition 72(2): 598S-606S 
This work is licensed under Creative Commons Attribution 4.0 License DOI: 10.19080/JOJPH.2019.04.555642
Your next submission with Juniper Publishers will reach you the below assets

- Quality Editorial service

- Swift Peer Review

- Reprints availability

- E-prints Service

- Manuscript Podcast for convenient understanding

- Global attainment for your research

- Manuscript accessibility in different formats

( Pdf, E-pub, Full Text, Audio)

- Unceasing customer service

Track the below URL for one-step submission https://juniperpublishers.com/online-submission.php 